CONTENTS OF CLINICAL HEMORHEOLOGY, VOLUME 14, NUMBER 5

J.F. Brun, A. El Bouhmadi, P. Boulot, O. Rousseau, F. Laffargue, J.L. Viala and A. Orsetti

J.F. Brun, P. Boulot, O. Rousseau, A. El Bouhmadi, F. Laffague, J.L. Viala and A. Orsetti

P.C. Buchan

P. Ruef and O. Linderkamp

R.G. Yoa, C. Corda, J.R. Rapin, L. Santona, H. Goudonnet, G. Rifle, A. Escousse,

R.C. Truchot and J. Mounie

C.G. Gustavsson, S.U. Persson, H. Larsson S. Persson

Md. A. Hussain, R.R. Puniyani and S. Kar
Conference Communications

Proceedings of the First International and Eighth European Conference on Clinical Hemorheology - Vienna, Austria, 5-8 July 1993 - Part VI

Symposium: Free SessionGynecology and Neonatology

637 Evaluation of erythrocyte hyperaggregation in fetal blood drawn by cordocentesis as a marker of fetal diseases

643 Modifications of erythrocyte aggregation during labor and delivery

651 Fetal deja vu of adult disease haemorheological associations between fetal intrauterine growth retardation and adult hypertension

659 Plastic deformation of erythrocyte membrane in full-term neonates and adults

Non-Conference Communications Papers

663 Hemorheological benefits of omega-3 polyunsaturated fatty acids on erythrocyte deformability in renal transplanted patients

677 Blood viscosity in relation to blood and haemoglobin concentration in healthy subjects and in patients with different cardiovascular diseases

685 Quantification of blood viscosity using power law model in cerebrovascular accidents and high risk controls 
M.A. Anwar and M.W. Rampling

F. Laghi Pasini, C. Frigerio, L. De Giorgi, L. Domini, S. Pecchi, P. Damiani, A. Acciavatti, P.L. Capecchi, N. Sodi, T. Provvedi, L. Volpi and T. Di Perri

W.J. Wong, H.H. Hu, Y.O. Luk and Y.K. Lo

S. Persson
697 Comparative hemorheology of five healthy, ethnically diverse groups:

Results of a pilot study

709 Effect of adenosine I.V. infusion on peripheral haemodynamics, haemorheology and platelet behaviour in man

723 The follow-up study of blood viscosity in the patients with acute ischemic stroke

\section{Dissertation Abstracts}

731 Erythrocyte deformability studied by viscometry and filtrometry

\section{Announcements}

733 Call for sending in dissertations, book (chapters), etc. - M.R. Hardeman

735 17th World Congress of the International Union of Angiology (London 3-7 April 1995)

738 Contents of Biorheology Volume 31, Number 3 